\title{
An Analysis of the Variability in Estimates of Bioenergetic Variables in Preterm Infants
}

\author{
KARL SCHULZE, MARK STEFANSKI, JULIA MASTERSON, SUDHA KASHYAP, \\ ULANA SANOCKA, MARY FORSYTH, RAJASEKHAR RAMAKRISHNAN, AND RALPH DELL \\ Human Infant Physiology Laboratory, Department of Pediatrics, College of Physicians and Surgeons, Columbia \\ University, and The Babies Hospital, New York, New York 10032
}

\begin{abstract}
Estimates of average daily energy expenditure and minimal observed oxygen consumption are commonly used to characterize the energy metabolism of neonates. Yet, the errors inherent in these estimates have not been defined. Using measurements of oxygen consumption and carbon dioxide production made in healthy growing low birth weight infants during eight consecutive 3 -h interfeeding epochs, we have determined the variability in the mean oxygen consumption, carbon dioxide production, respiratory quotient, total daily energy expenditure, and the minimal observed oxygen consumption among the feeding epochs. The coefficient of variation for oxygen consumption ranged from 3.1 to $9.1 \%$, for minimal observed oxygen consumption from 3.7 to $16.7 \%$, for carbon dioxide production from 3.3 to $7.4 \%$, and for total daily energy expenditure from 2.9 to $7.6 \%$. The SDs for respiratory quotient ranged from 0.008 to 0.066 . From these 24 -h data we have calculated the error in predicting daily estimates of the mean values for these variables if observations are made for less than $24 \mathrm{~h}$. As expected, this error decreases with increasing duration of observation. These data should prove useful in the design and interpretation of investigations of neonatal energy expenditure. (Pediatr Res 20: 422427, 1986)
\end{abstract}

\section{Abbreviations}

TDEE, total daily energy expenditure

BMR, basal metabolic rate

MOVO${ }_{2}$, minimal observed oxygen consumption

$\dot{\mathrm{V}} \mathrm{O}_{2}$, oxygen consumption

$\mathrm{VCO}_{2}$, carbon dioxide production

$\mathrm{RQ}$, respiratory quotient

LBW, low birth weight

SDA, specific dynamic action

Estimation of the TDEE of an infant, daily dietary intake of energy, and excretory loss of energy are required to compute changes in energy storage for a 24 -h period. Since direct measurement of gas exchange for the full 24-h period is onerous and frequently impossible, the accepted practice is to assume that the metabolic rate observed during several minutes or, at most,

Received October 21, 1985; accepted January 2, 1986

Correspondence Dr. Karl Schulze, College of Physicians and Surgeons of Columbia University, 3959 Broadway, New York, NY 10032.

Supported by the United States Public Health Service SCOR Grant HD13020, RR00645, and HL 14218. several hours of direct measurement is representative of the entire day and simply multiply the mean oxygen consumption per min by 1440 . This estimate is then taken to represent the metabolic rate of the infant for even longer periods of time, i.e. the days or weeks before and after the measurement period, because measurements of energy expenditure for even several hours each day are not practical for a balance study.

In addition to estimates of TDEE, investigators commonly desire a standard measurement of "resting" metabolic rate akin to the BMR of adults. However, frequent feedings, erratic physical activity patterns, inevitable thermal stress, and other factors make it difficult to obtain standard conditions for measuring resting metabolism in small infants. Investigators often use the $\mathrm{MOVO}{ }_{2}$ during a study interval to characterize the resting metabolic rate of infants. Since recordings of $\mathrm{MOVO}_{2}$ do not necessarily occur under exactly the same feeding, activity, and thermal conditions from one interfeeding period to the next, it is possible that they will vary considerably.

Regardless of whether the study requires estimation of minimal metabolic rate $\left(\mathrm{MOVO}_{2}\right)$ or estimation of long-term energy expenditure, it is important for investigators to know the reliability or error rate of these measurements. The purpose of this study was to determine the variance of estimates of both the total daily energy expenditure and the $\mathrm{MOVO}_{2}$ of an infant from direct measurements encompassing from one to eight feeding intervals by measuring $\dot{\mathrm{VO}}_{2}$ and $\dot{\mathrm{VCO}}_{2}$ and computing the RQ and energy expenditure for each of eight consecutive 3-h interfeeding periods in a group of LBW infants.

\section{METHODS}

We made continuous measurements of $\dot{\mathrm{VO}}_{2}$ and $\dot{\mathrm{V}} \mathrm{CO}_{2}$ for eight consecutive 3-h intervals on 12 occasions in five healthy, growing, LBW infants fed either human milk or artificial formula providing $120-150 \mathrm{kcal} / \mathrm{kg} \cdot$ day. The amount $(22.5 \mathrm{ml} / \mathrm{kg}$ per feeding) and the composition of feeding was the same for all feeds. The study was approved by the Institutional Review Board of Columbia University, College of Physicians and Surgeons and written informed parental consent was obtained for all studies. The subjects are described in Table 1.

Studies were performed in the Human Infant Physiology Laboratory located adjacent to the Neonatal Intensive Care Unit. Infants were placed in a plexiglass chamber positioned under a radiant warmer. Abdominal skin temperature was servo-controlled to $36.5^{\circ} \mathrm{C}$ in 10 studies. In two studies of larger infants, no external heat source was used. The heating system resembles an incubator system that is known to produce thermoneutral conditions when skin temperature is controlled at $36.5^{\circ} \mathrm{C}$ (1). However, the use of a radiant heater above a closed chamber may produce thermal conditions slightly different from those 
Table 1. Characteristics of the study population

\begin{tabular}{|c|c|c|c|c|c|}
\hline $\begin{array}{c}\text { Patient } \\
\text { no. }\end{array}$ & $\begin{array}{l}\text { Birth } \\
\text { wt (g) }\end{array}$ & $\begin{array}{c}\text { Gestational } \\
\text { age (wk) }\end{array}$ & $\begin{array}{c}\text { Study } \\
\text { no. }\end{array}$ & $\begin{array}{l}\text { Study } \\
\text { wt (g) }\end{array}$ & $\begin{array}{c}\mathrm{PCA}^{*} \text { at } \\
\text { study (wk) }\end{array}$ \\
\hline \multirow[t]{3}{*}{1} & 1200 & 29 & 1 & 990 & 31 \\
\hline & & & 2 & 1320 & 33 \\
\hline & & & 3 & 1490 & 35 \\
\hline \multirow[t]{3}{*}{2} & 1300 & 28 & 4 & 1130 & 30 \\
\hline & & & 5 & 1600 & 32 \\
\hline & & & 6 & 2220 & 34 \\
\hline \multirow[t]{4}{*}{3} & 930 & 31 & 7 & 910 & 33 \\
\hline & & & 8 & 1170 & 35 \\
\hline & & & 9 & 1590 & 37 \\
\hline & & & 10 & 1910 & 39 \\
\hline 4 & 1660 & 31 & 11 & 1510 & 33 \\
\hline 5 & 1050 & 29 & 12 & 1740 & 37 \\
\hline
\end{tabular}

* Postconceptional age.

produced by a commercial convective incubator or radiant warmer, and such differences may lead to more or less stability in the thermal environment.

$\dot{\mathrm{VO}}_{2}$ and $\dot{\mathrm{V}} \mathrm{CO}_{2}$ were measured continuously by open circuit indirect calorimetry using a differential paramagnetic oxygen analyzer (Servomex OA 184, Crowborough, Sussex, U.K.), an infrared carbon dioxide analyzer (Beckman LB-2, Sensormedics, Anaheim, CA), and a linear mass flowmeter (Matheson, E. Rutherford, NJ). Gas exchange was calculated as the product of gas flow through the metabolic chamber and difference in the concentrations of oxygen and carbon dioxide between the inlet and outlet of the metabolic chamber. Correction was made for effects of RQ on measurement of gas flow (2). Bench accuracy of this system is $2.2 \%$ (3). Urinary nitrogen was determined by analysis of a pooled 24-h urine collection obtained during the study (4). Heart rate, physical activity (5), skin temperature at two sites, and environmental temperature were also recorded. Data were available in digital form for each minute of the study for all variables.

Eleven of the 12 studies began after the $0800 \mathrm{~h}$ feeding and the 12 th study began after the $1100 \mathrm{~h}$ feeding. All studies lasted $24 \mathrm{~h}$ and consisted of eight successive interfeeding intervals, the average length being $152 \mathrm{~min}$. During the $24-\mathrm{h}$ study period, the infant was removed from the metabolic chamber every $3 \mathrm{~h}$ for feeding and routine nursing care; this accounted for an average duration of interrupted data of 28 min.

Raw data for the rate of gas flow through the metabolic chamber and oxygen and carbon dioxide concentrations were continuously recorded on a strip chart recorder and 1-min averages written on floppy discs at the end of each minute. Activity state was recorded each minute. At the end of each study, these data together with relevant clinical data were transferred to a larger computer for storage and analysis. The data were analyzed after editing and corrections for drift and RQ had been made. Conversion of the gas exchange and urinary nitrogen data to caloric expenditure was accomplished using the equations of Lusk (6).

Data analysis. The mean and SD of the eight epoch measurements of $\dot{\mathrm{VO}}{ }_{2}, \dot{\mathrm{V} C O}$, and $\mathrm{RQ}$ and caloric expenditure were computed for each study. Mean and SD of minimal $\dot{\mathrm{VO}}_{2}$, defined as the smallest mean of any five consecutive values, was also calculated for each of the 24 -h studies.

We made two separate computations of the error in predicting long term energy expenditure from shorter periods of direct measurement. First, we determined the error in predicting the mean value for all variables for a single, specific day (i.e. the day the measurements were made) using Formula 1, shown below: SD of day's estimated value

$$
\begin{aligned}
& =\sqrt{\frac{\frac{\Sigma(\text { SD of each study })^{2}}{12}}{\text { No. of epochs observed }}} \\
& \times\left(1-\frac{\text { No. of epochs observed }}{8}\right)
\end{aligned}
$$

The term $\Sigma(\mathrm{SD})^{2} / 12$ is the average epoch-to-epoch variance for all 12 studies. In this study, eight epochs were studied for each patient so a simple average is the same as a weighted average. Since we are interested in estimating the value of a variable for the day of the study, the more epochs studied, the more certain we become of this day's values. In fact, when all eight epochs are measured, this day's value is known precisely and the variance falls to zero. If one measures fewer than eight epochs, the remaining epochs have to be estimated. The best estimate available for the remaining epochs is the average of the observed epochs, and the best available variance estimate of the unobserved epochs is the variance of the observed epochs. The variance of the observed epochs is the average variance divided by the number of epochs or:

\section{$\Sigma\left[(\mathrm{SD})^{2} / 12\right] /$ no. of epochs observed}

The contribution of the variance of the unobserved epochs to the variance of the day's estimated value diminishes as the number of observed epochs increases. Thus, the variance of the unobserved epochs has to be weighted by ( 8 -number of epochs observed)/8. The square root converts to SD.

This computation implies that after eight epochs have been measured, the SD drops to zero and any error in the estimate is due solely to methodological factors. This computation may be of interest in situations where the value for a specific variable on a specific day is important, such as when TDEE is related to another variable measured at the same time, e.g. a thyroid function test.

A more interesting question, however, is how well a relatively short measurement characterizes the longer term $\dot{\mathrm{VO}}_{2}, \dot{\mathrm{V}} \mathrm{CO}_{2}$, $\mathrm{RQ}$, and caloric expenditure of the infant, i.e. how accurately a single, relatively brief measurement of $\mathrm{VO}_{2}, \dot{\mathrm{V} C O}, \mathrm{RQ}$, and caloric expenditure predicts the value for an infant over several days. The analysis directed at this question is done in the following manner. Mean values for each variable for each of the eight feeding epochs and the SD of these eight means were computed. These SDs were then squared, summed, and divided by the number of studies. The square root of this term, an estimate of the pooled or weighted mean SD of the epoch means for all 12 studies was then computed and divided by the square root of the number of epochs from one to eight. This analysis is summarized by formula 2, shown below:

$\mathrm{SD}$ of estimated daily value

$$
=\sqrt{\frac{\frac{\sum(\mathrm{SD} \text { of each study })^{2}}{12}}{\text { No. of epochs observed }}}
$$

As before $\Sigma(\mathrm{SD})^{2} / 12$ is the average epoch variance for all 12 studies. The goal here is to estimate a daily value, an estimate which is given by the mean of the observed epochs. The variance of this mean is the average epoch variance divided by the number of epochs observed and the square root of this variance is the $\mathrm{SD}$ of the estimated value.

This more general approach expresses the errors inherent in the fact that metabolic rate changes slightly from day to day. This calculation is more applicable to long-term studies of energy balance where relatively short periods of direct measurement are used to estimate average energy expenditure for days or weeks. 


\section{RESULTS}

Two plots of minute-to-minute measurements of $\dot{\mathrm{VO}}_{2}$ are shown in Figure 1. These plots illustrate the differences in the variability in measurements of $\mathrm{VO}_{2}$ within two interfeeding periods of the same infant. It is clear from these tracings that random, brief (e.g. $10 \mathrm{~min})$ sampling of $\mathrm{VO}_{2}$ would lead to substantial variation in estimates of the overall mean $\dot{\mathrm{VO}}_{2}$ for the interfeeding period, even when obtained at a fixed time after
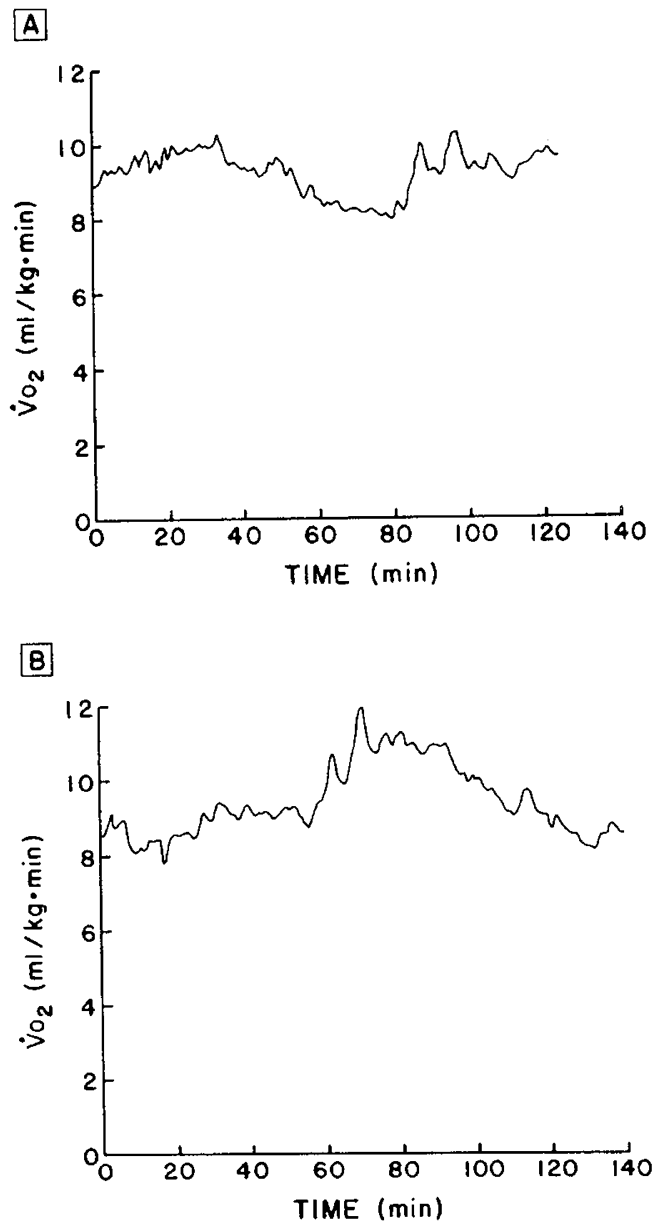

Fig. 1. Sequential plots of minute-to-minute measurements of oxygen consumption made during two interfeeding epochs in the same infant on the same day. Note the variability in $\mathrm{VO}_{2}$ within the epoch and the absence of a clear pattern related to the time after feeding. The mean $\dot{\mathrm{VO}_{2}}$ for the recordings were: $A, 9.26 \mathrm{ml} / \mathrm{kg} \cdot \min$ and $B, 9.35 \mathrm{ml} / \mathrm{kg} \cdot \mathrm{min}$. feeding. Variations in the measurements within epochs of the type shown in Figure 1 contribute to the differences in mean and minimal values among epochs.

The mean $\mathrm{VO}_{2}, \mathrm{VCO}_{2}, \mathrm{RQ}$, and computed caloric expenditure of each epoch for all studies and the mean and standard deviations of the epoch means are shown in Tables 2 to 5. The mean epoch means ranged from 6.80 to $9.67 \mathrm{ml} / \mathrm{kg} \cdot \min$ for $\mathrm{VO}_{2}$ and SD ranged from 0.27 to $0.72 \mathrm{ml} / \mathrm{kg} \cdot \mathrm{min}$. The mean epoch means for $\dot{\mathrm{VCO}}_{2}$ ranged from 6.10 to $9.38 \mathrm{ml} / \mathrm{kg} \cdot \mathrm{min}$ and $\mathrm{SD}$ from 0.28 to $0.66 \mathrm{ml} / \mathrm{kg} \cdot \mathrm{min}$. The mean epoch RQ ranged from 0.901 to 1.064 with S.D. from 0.008 to 0.066 . Mean epoch mean caloric expenditure ranged from 48.1 to $68.8 \mathrm{cal} / \mathrm{kg}$. day with SD from 1.9 to $5.1 \mathrm{kcal} / \mathrm{kg} \cdot$ day. The correlation between the SD of the epoch means and their absolute levels ranged from $r=$ 0.02 to 0.27 . Since the data are homoscedastic, we used the SD in our analysis. The $\mathrm{MOVO}_{2}$ for each epoch and the SD of the individual study minimal values are shown in Table 6 . The mean of the eight minimal values ranged from 5.96 to $8.03 \mathrm{ml} / \mathrm{kg} \cdot \mathrm{min}$ and the standard deviation of the minimum values ranged from 0.28 to $1.27 \mathrm{ml} / \mathrm{kg} \cdot \mathrm{min}$.

The effects of including different numbers of feeding epochs in the prediction of the mean daily value of the variables, using both formulas 1 and 2 are shown in Table 7 . Note that after eight epochs the SD computed by formula 1 is zero since direct measurements encompassed the entire day. The effect of increasing lengths of observations on the prediction of TDEE using formula 2 includes a residual $S D$, a reflection of the the fact that metabolic rate is not constant from day to day and, hence, even a full days direct study can only be assumed to reflect the condition of the infant within the confidence limits shown in Table 6.

\section{DISCUSSION}

Measurements of $\mathrm{VO}_{2}$ for short periods of time have indicated that the variability in metabolic rate from infant to infant is quite large (7). Since these measurements were made for relatively brief periods of time, it is likely that some of this variance is due to variations in factors such as time in relation to last feeding, amount of physical activity, and thermal conditions at the time of the measurement. In addition there are differences among infants and technical and methodological factors which can contribute to the observed error rate. Measurements of oxygen consumption made continuously in the same infants for $24 \mathrm{~h}$ have shown that the rate of energy expenditure of an individual infant ranges widely during the course of the day (8). The authors suggested that periods of observation less than $6 \mathrm{~h}$ might lead to considerable error; however, the error was not determined quantitatively. Others have stated that the variance of sequential, $90-$ to 180 -min measurements of $\mathrm{VO}_{2}$ in the same infant over 24 to $48 \mathrm{~h}$ was relatively small (9), but the data were not reported.

Using sequential 3-h studies of the same infant, under the

Table 2. Epoch means for $\dot{\mathrm{V}} \mathrm{O}_{2}[\mathrm{ml} /(\mathrm{kg} \cdot \mathrm{min})]$ and mean and $S D$ of the eight epochs for each patient

\begin{tabular}{|c|c|c|c|c|c|c|c|c|c|c|}
\hline \multirow[b]{2}{*}{ Patient no. } & \multicolumn{8}{|c|}{ Epoch no. } & \multirow[b]{2}{*}{ Mean } & \multirow[b]{2}{*}{$\mathrm{SD}$} \\
\hline & 1 & 2 & 3 & 4 & 5 & 6 & 7 & 8 & & \\
\hline 1 & 5.97 & 6.88 & 7.51 & 7.02 & 7.13 & 6.24 & 6.94 & 6.71 & 6.80 & 0.49 \\
\hline 2 & 8.41 & 7.96 & 7.34 & 6.95 & 7.28 & 8.51 & 8.17 & 6.64 & 7.66 & 0.70 \\
\hline 3 & 7.32 & 7.99 & 8.66 & 8.39 & 8.36 & 9.12 & 8.29 & 8.26 & 8.30 & 0.52 \\
\hline 4 & 6.22 & 7.42 & 7.08 & 7.02 & 7.24 & 7.43 & 8.08 & 7.87 & 7.29 & 0.57 \\
\hline 5 & 8.32 & 8.85 & 8.78 & 9.34 & 8.81 & 8.82 & 8.83 & 8.80 & 8.82 & 0.27 \\
\hline 6 & 9.03 & 8.55 & 8.92 & 8.26 & 9.19 & 8.24 & 8.59 & 8.66 & 8.68 & 0.34 \\
\hline 7 & 7.70 & 8.40 & 8.10 & 7.99 & 8.53 & 8.21 & 7.86 & 8.08 & 8.11 & 0.27 \\
\hline 8 & 9.34 & 9.47 & 10.17 & 9.26 & 9.28 & 9.43 & 9.74 & 9.18 & 9.48 & 0.32 \\
\hline 9 & 8.65 & 9.38 & 9.86 & 9.44 & 9.70 & 9.77 & 8.96 & 9.41 & 9.40 & 0.41 \\
\hline 10 & 9.34 & 9.55 & 9.75 & 8.29 & 9.43 & 9.66 & 10.46 & 8.34 & 9.35 & 0.72 \\
\hline 11 & 6.81 & 7.02 & 7.27 & 7.62 & 8.03 & 8.13 & 7.24 & 6.86 & 7.38 & 0.51 \\
\hline 12 & 10.85 & 9.05 & 9.19 & 9.22 & 9.56 & 10.38 & 9.53 & 9.62 & 9.67 & 0.63 \\
\hline Means & & & & & & & & & 8.41 & 0.50 \\
\hline
\end{tabular}


Table 3. Epoch means for $\dot{V} \mathrm{CO}_{2}[\mathrm{ml} /(\mathrm{kg} \cdot \mathrm{min})]$ and mean and $\mathrm{SD}$ of the eight epochs for each patient

\begin{tabular}{|c|c|c|c|c|c|c|c|c|c|c|}
\hline \multirow[b]{2}{*}{ Patient no. } & \multicolumn{8}{|c|}{ Epoch no. } & \multirow[b]{2}{*}{ Mean } & \multirow[b]{2}{*}{$\mathrm{SD}$} \\
\hline & 1 & 2 & 3 & 4 & 5 & 6 & 7 & 8 & & \\
\hline 1 & 5.55 & 5.98 & 5.95 & 6.82 & 6.53 & 6.16 & 5.84 & 5.96 & 6.10 & 0.40 \\
\hline 2 & 8.30 & 7.95 & 7.61 & 7.26 & 7.51 & 8.67 & 7.73 & 6.88 & 7.74 & 0.57 \\
\hline 3 & 8.24 & 8.14 & 8.79 & 7.98 & 8.22 & 8.52 & 8.52 & 8.64 & 8.38 & 0.28 \\
\hline 4 & 6.69 & 7.37 & 7.38 & 6.93 & 7.54 & 7.31 & 7.81 & 7.58 & 7.33 & 0.36 \\
\hline 5 & 9.07 & 9.17 & 8.93 & 9.83 & 9.35 & 9.35 & 9.76 & 9.56 & 9.38 & 0.32 \\
\hline 6 & 9.55 & 9.05 & 9.44 & 8.75 & 9.59 & 8.80 & 9.08 & 9.27 & 9.19 & 0.33 \\
\hline 7 & 7.23 & 8.40 & 7.89 & 8.26 & 7.83 & 7.80 & 7.82 & 7.77 & 7.87 & 0.35 \\
\hline 8 & 8.68 & 9.25 & 9.98 & 9.08 & 9.25 & 9.53 & 9.53 & 8.55 & 9.23 & 0.47 \\
\hline 9 & 8.03 & 8.90 & 9.60 & 9.01 & 9.13 & 9.49 & 8.56 & 8.74 & 8.93 & 0.51 \\
\hline 10 & 8.89 & 9.49 & 9.46 & 8.17 & 9.20 & 9.21 & 9.59 & 7.78 & 8.97 & 0.66 \\
\hline 11 & 6.48 & 6.43 & 6.64 & 7.05 & 7.40 & 7.13 & 6.96 & 6.56 & 6.83 & 0.35 \\
\hline 12 & 9.61 & 8.51 & 8.85 & 8.45 & 8.69 & 10.04 & 8.65 & 8.81 & 8.95 & 0.56 \\
\hline Means & & & & & & & & & 8.24 & 0.45 \\
\hline
\end{tabular}

Table 4. Epoch means for $R Q$ and mean and $S D$ of the eight epochs for each patient

\begin{tabular}{|c|c|c|c|c|c|c|c|c|c|c|}
\hline \multirow[b]{2}{*}{ Patient no. } & \multicolumn{8}{|c|}{ Epoch no. } & \multirow[b]{2}{*}{ Mean } & \multirow[b]{2}{*}{ SD } \\
\hline & 1 & 2 & 3 & 4 & 5 & 6 & 7 & 8 & & \\
\hline 1 & 0.936 & 0.870 & 0.794 & 0.973 & 0.914 & 0.989 & 0.844 & 0.892 & 0.901 & 0.066 \\
\hline 2 & 0.989 & 1.001 & 1.038 & 1.047 & 1.033 & 1.018 & 0.947 & 1.043 & 1.014 & 0.034 \\
\hline 3 & 1.126 & 1.019 & 1.018 & 0.952 & 0.983 & 0.936 & 1.029 & 1.048 & 1.014 & 0.060 \\
\hline 4 & 1.079 & 0.991 & 1.043 & 0.988 & 1.043 & 0.983 & 0.966 & 0.964 & 1.007 & 0.042 \\
\hline 5 & 1.089 & 1.035 & 1.017 & 1.053 & 1.063 & 1.058 & 1.106 & 1.086 & 1.064 & 0.029 \\
\hline 6 & 1.058 & 1.059 & 1.058 & 1.059 & 1.045 & 1.067 & 1.055 & 1.070 & 1.059 & 0.008 \\
\hline 7 & 0.942 & 1.000 & 0.973 & 1.035 & 0.920 & 0.950 & 0.995 & 0.962 & 0.972 & 0.037 \\
\hline 8 & 0.929 & 0.977 & 0.980 & 0.979 & 0.996 & 1.011 & 0.975 & 0.932 & 0.972 & 0.028 \\
\hline 9 & 0.926 & 0.947 & 0.970 & 0.952 & 0.939 & 0.968 & 0.946 & 0.925 & 0.947 & 0.017 \\
\hline 10 & 0.942 & 0.993 & 0.967 & 1.156 & 0.974 & 0.947 & 0.905 & 0.932 & 0.977 & 0.077 \\
\hline 11 & 0.952 & 0.917 & 0.914 & 0.925 & 0.922 & 0.877 & 0.962 & 0.956 & 0.928 & 0.028 \\
\hline 12 & 0.886 & 0.940 & 0.963 & 0.920 & 0.909 & 0.985 & 0.909 & 0.917 & 0.929 & 0.032 \\
\hline Means & & & & & & & & & 0.982 & 0.043 \\
\hline
\end{tabular}

Table 5. Epoch means for energy expenditure $[\mathrm{kcal} /(\mathrm{kg} \cdot \mathrm{day})]$ and mean and SD of the eight epochs for each patient

\begin{tabular}{|c|c|c|c|c|c|c|c|c|c|c|}
\hline \multirow[b]{2}{*}{ Patient no. } & \multicolumn{8}{|c|}{ Epoch no. } & \multirow[b]{2}{*}{ Mean } & \multirow[b]{2}{*}{$\mathrm{SD}$} \\
\hline & 1 & 2 & 3 & 4 & 5 & 6 & 7 & 8 & & \\
\hline 1 & 42.5 & 48.3 & 51.7 & 50.6 & 50.7 & 45.1 & 48.4 & 47.4 & 48.1 & 3.1 \\
\hline 2 & 60.8 & 57.6 & 53.6 & 50.9 & 53.2 & 62.0 & 58.4 & 48.6 & 55.6 & 4.8 \\
\hline 3 & 54.7 & 58.2 & 63.0 & 60.1 & 60.4 & 65.1 & 60.5 & 60.6 & 60.3 & 3.1 \\
\hline 4 & 45.9 & 53.7 & 51.8 & 50.7 & 53.0 & 53.6 & 58.1 & 56.5 & 52.9 & 3.7 \\
\hline 5 & 61.6 & 64.7 & 63.9 & 68.5 & 64.8 & 64.9 & 65.6 & 65.1 & 64.9 & 1.9 \\
\hline 6 & 66.3 & 62.8 & 65.5 & 60.7 & 67.2 & 60.6 & 63.0 & 63.8 & 63.7 & 2.5 \\
\hline 7 & 54.9 & 60.8 & 58.3 & 58.3 & 60.6 & 58.8 & 56.9 & 58.0 & 58.3 & 1.9 \\
\hline 8 & 66.4 & 68.1 & 73.3 & 66.7 & 67.1 & 68.5 & 70.1 & 65.3 & 68.2 & 2.5 \\
\hline 9 & 61.4 & 67.0 & 70.8 & 67.5 & 69.2 & 70.2 & 64.1 & 66.9 & 67.1 & 3.1 \\
\hline 10 & 66.9 & 69.1 & 70.1 & 59.8 & 67.9 & 69.2 & 74.3 & 59.4 & 67.1 & 5.1 \\
\hline 11 & 48.7 & 49.8 & 51.5 & 54.2 & 57.1 & 57.1 & 51.9 & 49.1 & 52.4 & 3.4 \\
\hline 12 & 76.4 & 64.6 & 66.0 & 65.5 & 67.7 & 74.6 & 67.5 & 68.3 & 68.8 & 4.3 \\
\hline Means & & & & & & & & & 60.6 & 3.4 \\
\hline
\end{tabular}

same conditions, for a full 24-h day, we have estimated the accuracy in estimating the total daily $\dot{\mathrm{VO}}_{2}, \dot{\mathrm{V}} \mathrm{CO}_{2}, \mathrm{RQ}$, and computed TDEE from periods of time less than $24 \mathrm{~h}$. These quantitative estimates of accuracy will permit investigators to design experimental studies of the metabolic rate of infants because the number of studies and/or the length of the measurements can now be determined more precisely according to the size of the difference in expected outcomes and the number of available patients.

The variability in metabolic rate among feeding epochs must arise from variations in the measurement of one or more components of the TDEE: BMR, SDA, the energy cost of activity, and/or the energy expended to maintain thermal stability. Energy expenditure related to thermal stress is negligible under thermoneutral conditions leaving variations in BMR, SDA, or physical activity as potential causes of variation in TDEE.

Since healthy growing LBW infants are never fasted long enough for the SDA from one feeding to dissipate totally before the next feeding, basal metabolic rate is not measurable. If fasting is attempted, alterations in activity due to hunger prohibit the infant from reaching a steady state resting condition. Because BMR cannot be independently determined with current methodologies, the possibility cannot be excluded that variability in $\mathrm{BMR}$, perhaps related to diurnal factors or individual differences in hormonal profiles, contributes to the overall variability in our estimates of all variables. 
Table 6. Minimal $\dot{V} \mathrm{O}_{2}$ for each epoch and mean and SD of the eight minimal values for each patient

\begin{tabular}{|c|c|c|c|c|c|c|c|c|c|c|}
\hline \multirow[b]{2}{*}{ Patient no. } & \multicolumn{8}{|c|}{ Epoch no. } & \multirow[b]{2}{*}{ Mean } & \multirow[b]{2}{*}{$\mathrm{SD}$} \\
\hline & 1 & 2 & 3 & 4 & 5 & 6 & 7 & 8 & & \\
\hline 1 & 5.05 & 6.43 & 6.71 & 6.04 & 6.46 & 5.40 & 5.71 & 5.93 & 5.96 & 0.57 \\
\hline 2 & 6.83 & 6.84 & 6.58 & 6.03 & 6.48 & 7.85 & 6.85 & 4.59 & 6.51 & 0.93 \\
\hline 3 & 6.25 & 6.87 & 7.20 & 7.28 & 7.46 & 7.66 & 7.17 & 7.37 & 7.16 & 0.43 \\
\hline 4 & 5.54 & 5.94 & 6.46 & 5.68 & 5.94 & 6.42 & 6.43 & 6.46 & 6.11 & 0.38 \\
\hline 5 & 7.20 & 7.43 & 7.40 & 7.99 & 7.64 & 7.92 & 7.47 & 7.35 & 7.55 & 0.28 \\
\hline 6 & 8.11 & 7.47 & 7.98 & 7.26 & 8.20 & 6.58 & 7.26 & 7.28 & 7.52 & 0.55 \\
\hline 7 & 6.84 & 7.50 & 7.14 & 7.29 & 7.74 & 7.04 & 6.31 & 7.02 & 7.11 & 0.43 \\
\hline 8 & 8.27 & 8.20 & 8.94 & 7.79 & 8.10 & 7.94 & 7.84 & 7.16 & 8.03 & 0.50 \\
\hline 9 & 6.81 & 7.18 & 8.03 & 7.63 & 6.74 & 7.29 & 7.49 & 7.30 & 7.31 & 0.42 \\
\hline 10 & 7.04 & 7.70 & 6.85 & 6.81 & 6.64 & 7.75 & 8.25 & 7.08 & 7.26 & 0.57 \\
\hline 11 & 6.12 & 6.17 & 6.12 & 6.27 & 6.64 & 6.83 & 5.80 & 6.10 & 6.26 & 0.33 \\
\hline 12 & 9.12 & 7.71 & 8.50 & 5.35 & 8.65 & 6.32 & 7.18 & 7.93 & 7.60 & 1.27 \\
\hline Means & & & & & & & & & 7.03 & 0.62 \\
\hline
\end{tabular}

Table 7. SDs of predicted values of bioenergetic variables with increasing length of direct measurement

\begin{tabular}{|c|c|c|c|c|c|c|c|c|}
\hline & \multicolumn{8}{|c|}{$\begin{array}{l}\text { SD of predicted value by epoch no. } \\
\text { Formula } 1\end{array}$} \\
\hline & 1 & 2 & 3 & 4 & 5 & 6 & 7 & 8 \\
\hline$\dot{\mathrm{V}} \mathrm{O}_{2}[\mathrm{ml} /(\mathrm{kg} \cdot \min )]$ & 0.44 & 0.27 & 0.18 & 0.12 & 0.08 & 0.05 & 0.02 & 0.00 \\
\hline$\dot{\mathrm{V} C O}{ }_{2}(\mathrm{mg} /(\mathrm{kg} \cdot \mathrm{min})]$ & 0.39 & 0.24 & 0.16 & 0.11 & 0.08 & 0.05 & 0.02 & 0.00 \\
\hline $\mathrm{RQ}$ & 0.037 & 0.022 & 0.016 & 0.010 & 0.007 & 0.004 & 0.002 & 0.00 \\
\hline $\begin{array}{l}\text { Energy expenditure [kcal/ } \\
(\mathrm{kg} \cdot \mathrm{day})]\end{array}$ & 3.0 & 1.8 & 1.2 & 0.8 & 0.6 & 0.3 & 0.2 & 0.00 \\
\hline \multirow{2}{*}{$\begin{array}{l}\text { Minimum } \\
\text { min })]\end{array}$} & 0.54 & 0.33 & 0.22 & 0.16 & 0.10 & 0.06 & 0.03 & 0.00 \\
\hline & \multicolumn{8}{|c|}{ Formula 2} \\
\hline$\dot{\mathrm{V}} \mathrm{O}_{2}[\mathrm{ml} /(\mathrm{kg} \cdot \min )]$ & 0.50 & 0.35 & 0.29 & 0.25 & 0.22 & 0.20 & 0.19 & 0.18 \\
\hline$\dot{\mathrm{V} C O}{ }_{2}[\mathrm{ml} /(\mathrm{kg} \cdot \mathrm{min})]$ & 0.45 & 0.32 & 0.26 & 0.22 & 0.20 & 0.18 & 0.17 & 0.16 \\
\hline $\mathrm{RQ}$ & 0.043 & 0.030 & 0.025 & 0.022 & 0.019 & 0.018 & 0.016 & 0.015 \\
\hline $\begin{array}{l}\text { Energy expenditure }[\mathrm{kcal} / \\
\quad(\mathrm{kg} \cdot \mathrm{day})]\end{array}$ & 3.4 & 2.4 & 2.0 & 1.7 & 1.5 & 1.4 & 1.3 & 1.2 \\
\hline $\begin{array}{l}\text { Minimum } \mathrm{VO}_{2}[\mathrm{ml} /(\mathrm{kg} \text {. } \\
\text { min })]\end{array}$ & 0.62 & 0.44 & 0.36 & 0.31 & 0.28 & 0.25 & 0.23 & 0.22 \\
\hline
\end{tabular}

So little is known about the magnitude and duration of SDA in growing infants that it is possible to discuss this phenomenon in only the most general terms. There is little question that TDEE cycles with feeding (10), although the amplitude and frequency of the cycles are not well defined $(11,12)$. It is likely that the magnitude of the SDA effect is related to the quantity of dietary intake (13). The traditional belief that the quality of dietary intake strongly and consistently influences SDA is less clear (14); rather, all substrates apparently contribute to the SDA. Such factors as the basal nutritional state and the rate of growth may also influence the SDA in neonates, as they do in malnourished infants (15). Our study infants were fed identical amounts of the same formula at each of the eight feedings. Therefore, to the degree that SDA is determined by the quantity and/or quality of nutrient intake, variations among the feeding periods should remain constant. Nonetheless, it seems likely that SDA is subject to some inherent variability. Therefore, some of the overall variability in TDEE may be due to variations in SDA over the time of the measurements. The data plotted in Figure 1 illustrate differences in the variability in the measurement of $\mathrm{VO}_{2}$ following feeding.

Since small babies spend approximately $90 \%$ of their time sleeping, changes in the physical activity of LBW infants are largely due to changes in the distribution of quiet and active sleep. The difference in metabolic rate between quiet and active sleep is approximately $10 \%$ in both preterm and term neonates (16). Because infants cycle irregularly between quiet and active sleep during the entire postprandial interval, the contribution of the energy cost of sleep-related physical activity to total energy expenditure may vary. Changes in metabolic rate related to activity are superimposed on the changes due to SDA; thus, although some of the variability in metabolic rate clearly is due to differences in physical activity, it is not possible to estimate the magnitude of this effect accurately without concurrent accurate estimates of SDA.

The variability in $\mathrm{MOV}_{2}$ of individual infants among the eight postprandial intervals is considerable; SDs for minimal $\mathrm{VO}_{2}$ ranged from 0.28 to $1.27 \mathrm{ml} / \mathrm{kg} \cdot \mathrm{min}$. One would expect $\mathrm{MOVO}_{2}$ to occur during quiet sleep immediately before the feeding since this is the time when the physical activity and SDA contributions to the overall $\dot{\mathrm{VO}}_{2}$ are minimal. Unfortunately, quiet sleep accounts for less than $15 \%$ of sleep time in LBW infants and does not occur consistently in the immediate preprandial period. Hence, the coincidence of quiet sleep and minimal SDA is unlikely. More commonly, the $\mathrm{MOVO}_{2}$ is recorded either during quiet sleep with a residual contribution of SDA from the preceeding feeding or during active sleep with minimum SDA. This variable relationship between SDA and activity leads to variability in the recorded value for $\mathrm{MOVO}_{2}$.

It should be emphasized that these data were obtained in healthy, growing LBW infants, all with a postconceptional age of less than $40 \mathrm{wk}$. The variability in estimates of energetic variables in well, term infants as well as in sick and/or semistarved preterm and term infants may be entirely different. In 
addition, we have considered only continuous measurements of the total postprandial period. Measurements of shorter intervals or measurements that include the feeding process, nursing procedures, or medical interventions are likely to produce even more variability. In view of all of the factors causing variability in metabolic gas exchange, it is clear that measurements of $\mathrm{VO}_{2}$ and $\dot{\mathrm{VCO}}_{2}$ made for less than a complete postprandial period have little value in estimating long-term oxygen consumption.

\section{REFERENCES}

1. Silverman WA, Sinclair JC, Agate FJ 1966 Oxygen cost of minor variations in heat balance of small newborn infants. Acta Paediatr Scand 55:294

2. Lister G, Hoffman J, Rudolph AM 1974 Oxygen uptake in infants and children: a simple method for measurement. Pediatrics 53:656-662

3. Schulze K, Kairam R, Stefanski M, Sciacca R, James LS 1981 Continuous measurement of minute ventilation and gaseous metabolism of newborn infants. J Appl Physiol 50:1098-1103

4. Ebeling M. The Duncan method for nitrogen in feeds. J AOAC 1968; 51:766

5. Stefanski M, Schulze K, Bateman D, Kairam R, Pedley T, Masterson J, James LS 1984 A scoring system for states of sleep and wakefulness in term and preterm infants. Pediatr Res 18:58-62

6. Lusk G 1961 Basal metabolism standards. In: Diem K (ed) Geigy Scientific Tables, 6th Ed. Documenta Geigy, Montreal, p 628
7. Rutter N, Brown SM, Hull D 1978 Variations in the resting oxygen consumption of small babies. Arch Dis Child 53:850-854

8. Abdulrazzaq YM, Brooke OG 1984 Respiratory metabolism in preterm infants: the measurement of oxygen consumption during prolonged periods. Pediat Res 18.928-931

9. Gudinchet F, Schutz Y, Micheli JL, Stettler E, Jequier E 1982 Metabolic cost of growth in very low birth weight infants. Pediatr Res 16:1025-1030

10. Brooke OG, Alvear J, Arnold M 1979 Energy metabolism, energy expenditure and growth in healthy immature infants. Pediatr Res 13:215-220

11. Mestyan J, Jarai I, Kekete M, Soltesz GY 1969 Specific dynamic action in premature infants kept at and below the neutral temperature. Pediatr Res 3:41-50

12. Stothers JK, Warner RM 1979 Effect of feeding on neonatal oxygen consumption. Arch Dis Child 54:415-420

13. Askenazi J, Nordenstrom J, Rosenbaum SH, Elwyn DH, Hyman AI, Carpentier YA, Kinney JM 1981 Nutrition for the patient with respiratory failure: glucose vs. fat. Anesthesiology 54:373-377

14. Editorial 1972 Not so "specific" dynamic action. Nutr Rev 30:133-135

15. Ashworth A 1969 Metabolic rates during recovery from protein caloric malnutrition: the need for a new concept of specific dynamic action. Nature 223:407-409

16. Stothers JK, Warner RM 1978 Oxygen consumption and neonatal sleep states. J Physiol 278:435-440

17. Schulze K, Kairam R, Stefanski M, Sciacca R, Bateman D, Dell R, James LS 1981 Spontaneous variability in minute ventilation, oxygen consumption and heart rate of low birth weight infants. Pediatr Res 15:1111-1116 